\title{
Design of Aperture Coupled Micro-Strip patch Antenna for Wireless Communication applications at 5.8Ghz
}

\author{
Tanveer Kour Raina ${ }^{1}$ Mrs. Amanpreet Kaur ${ }^{2}$ Mr. Rajesh Khanna ${ }^{3}$ \\ 1.M.E., Student, ECED, Thapar University, Patiala \\ 2.Assitt.ProfessorECED Thapar University, Patiala \\ 3 Professor, ECED Thapar University, Patiala
}

Abstract: - In this paper, a simple aperture coupled microstrip antenna at a frequency band of $5.75 \mathrm{GHz}$ to 5.85 , is presented. Here, substrates with thickness of $1.57 \mathrm{~mm}$ is used, both the substrates having same thickness are considered. In this, the optimization of antenna design is done using $3 D$ electromagnetic simulator. This antenna is useful for wireless communication.

Key words: - Micro-strip patch antenna, slot, Aperture coupling, VSWR, return loss, bandwidth, radiation pattern, gain, directivity.

\section{Introduction:}

A microstrip antenna is basically a low profile antenna with a number of advantages over other antennas like small in size, light weight, inexpensive to fabricate.[1] A microstrip antenna with aperture coupled feeding technique is used here as it is one of the most important method for exciting microstrip antenna and its analysis has been shown here.

In ACMPA, the radiating element (patch) and feed line are separated by conductive layer (ground) between them.[2] The two are electromagnetically coupled through an aperture on the ground. The antenna can be optimized for a desired performance in terms of gain, bandwidth and VSWR by varying its parameters (L, W, slot dimensions)

\section{Design and Analysis of ACMPA:}

In ACMPA as, there are two dielectric substrates, one above the ground and second beneath the ground. A patch is printed over the low dielectric constant substrate above the ground and the feed is printed beneath the high dielectric constant substrate below the ground. Patch and feed line are electromagnetically coupled through an aperture made on the ground. As it can see from the figure 1, there are two dielectric slabs with height $h_{1}$ and $h_{2}$. There is a feed line on the lower substrate and patch on the upper substrate; slot is cut on the ground. For maximum coupling, slot is centered below the patch and also feed line should be at right angle to the slot.[3] Such a design can be well explained with the help of following diagram:

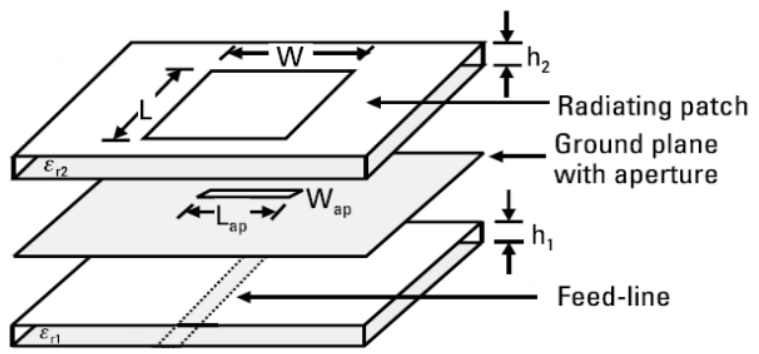

Figure 1

\section{A. Design of Microstrip Patch Antenna:}

The design of the antenna is done using the following considerations as mentioned in the equations given below. Mostly the length (L) and width (W) of the patch can be calculated using the parameters like height of the substrate $\left(h_{2}\right)$ below the patch and the dielectric constant $\left(\varepsilon_{\mathrm{r} 2}\right)$ and the resonant frequency $\left(\mathrm{f}_{\mathrm{r}}\right)$ which are given.

The formulas for calculating length (L) and width (W) are:

$$
\begin{array}{r}
\mathrm{W}=\frac{1}{2 f r \sqrt{(\mu o \varepsilon o)}} \sqrt{\frac{2}{\varepsilon r+1}}=\frac{V o}{2 f r} \sqrt{\left(\frac{2}{\varepsilon r+1}\right) \ldots .} \\
\mathrm{L}=\frac{1}{2 f r \sqrt{(\varepsilon r e f f) \sqrt{(\varepsilon o \mu o)}}-2 \Delta L \ldots \ldots \ldots \ldots \text { (ii) }}
\end{array}
$$


Where Vo is the speed of light.

the height of the substrate is not given then it can be calculated using resonant frequency and the dielectric constant of the substrate. [4] The formula is:

$$
\mathrm{h} \leq \frac{0.3 V_{o}}{2 \pi f r \sqrt{\varepsilon r}}
$$

\section{B. Design of the microstrip feed line:}

Usually $50 \Omega$ microstrip line is used to feed the radiating patch. Feed line width decides the characteristic impedance of the feed line, so chosen to get the required impedance. Also for maximum coupling, the feed line must be placed perpendicular to the center of the slot.

\section{Design of the Aperture:}

The amount of the coupling between the patch and feed line is determined by the aperture, so aperture has a very important role in the microstrip antenna with aperture coupled feeding. Mostly the length of the aperture (Lap) and the stub length are considered and width of the aperture $\left(\mathrm{W}_{\mathrm{ap}}\right)$ is small usually $1 \mathrm{~mm}$ is considered.

\section{Design of the stub:}

Stub length is considered as the length after the feed line. It is used to tune the excess reactance of the aperture. The optimization is done using $3 \mathrm{D}$ electromagnetic simulator and the variations of the stub lengths are optimized.

\section{Values of the design parameters:} below: [1]

For final designing of the ACMPA with accurate parameters, the values of the parameters are given

\begin{tabular}{|l|l|}
\hline $\begin{array}{l}\text { Dielectric constant (Er) } \\
\text { (both of the substrate have } \\
\text { same values) }\end{array}$ & 4.4 \\
\hline Thickness of the substrate & $1.57 \mathrm{~mm}$ \\
\hline Length of the patch (Lp) & $14.8 \mathrm{~mm}$ \\
\hline Width of the patch (Wp) & $9.53 \mathrm{~mm}$ \\
\hline Width of the aperture (Wap) & $2.4 \mathrm{~mm}$ \\
\hline Length of the aperture (Lap) & $8 \mathrm{~mm}$ \\
\hline Width of the feed line (Wf) & $6 \mathrm{~mm}$ \\
\hline Length of the stub (Lfs) & $8 \mathrm{~mm}$ \\
\hline
\end{tabular}

Design:

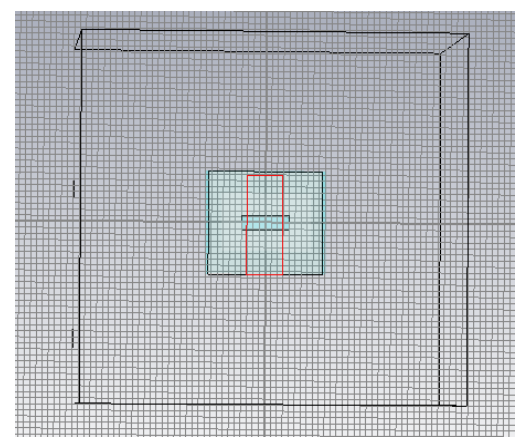

Figure 2 Antenna Design 
The results are shown below:

1) The plot of return loss against frequency.

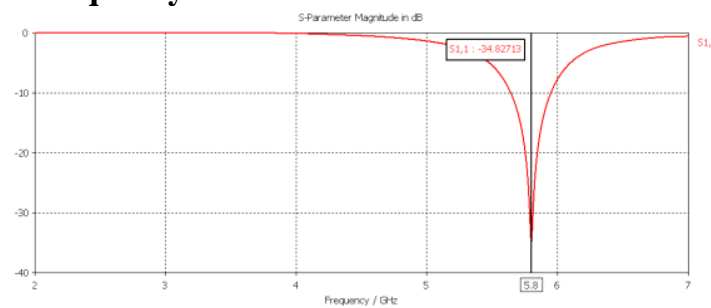

Figure 3 Return Loss

\section{2) Impedance measured using smith chart}

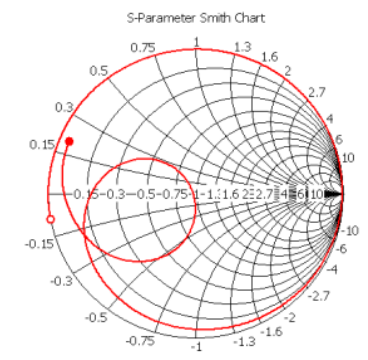

$\mathrm{si,1}(50 \mathrm{chm})$

Figure 4 Smith Chart

\section{3) Directivity:}

at a frequency of $5.8 \mathrm{GHz}$, directivity is $5.652 \mathrm{dBi}$, radiation pattern obtained is omnidirectional with main lobe directed at an angle of 7.0 degree, having angular beamwidth of 100.0 degree. The magnitude of the main lobe is $5.7 \mathrm{dBi}$

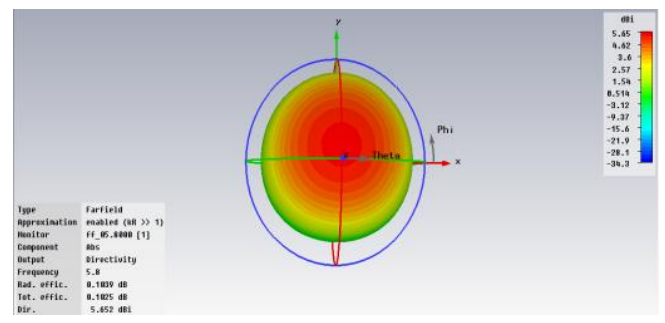

Figure 5 (a)

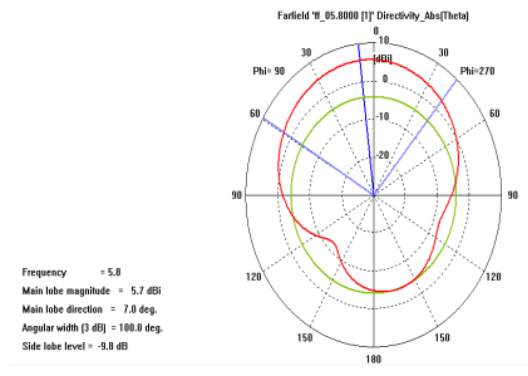

Figure 5 (b) Directivity

\section{4) Gain}

At a frequency of $5.8 \mathrm{GHz}$, gain is $5.756 \mathrm{~dB}$, radiation pattern obtained is omnidirectional with main lobe directed at an angle of 7.0 degree, having angular beamwidth of 100.0 degree. The magnitude of the main lobe is $5.8 \mathrm{~dB}$. 


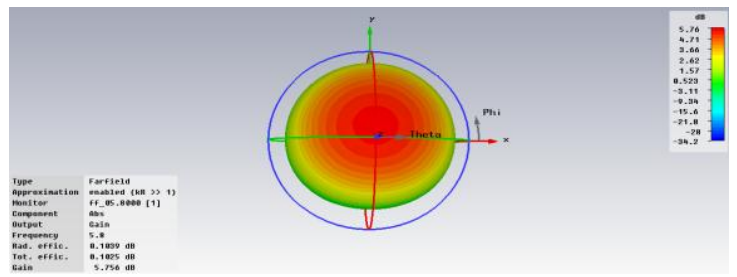

6)Figure 6(a)
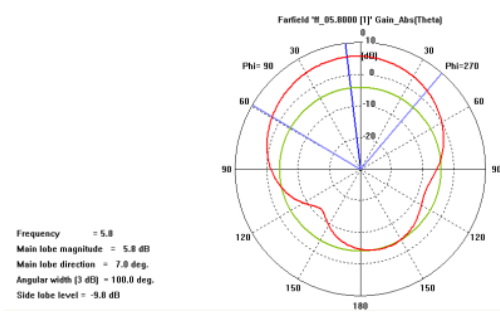

Figure 6(b) Gain of Antenna

\section{5) VSWR}

When a transmitter is connected to an antenna by a feed line, the impedance of the antenna and feed line must match exactly for maximum energy transfer from the feed line to the antenna to be possible. When an antenna and feed line do not have matching impedances, some of the electrical ener gy cannot be transferred from the feed line to the antenna. Energy not transferred to the antenna is reflected back towards the transmitter. It is the interactio $n$ of these reflected waves with forward waves which causes standing wave patterns.

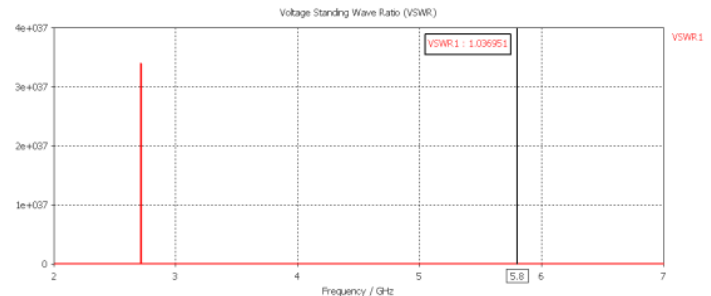

Figure 7 VSWR

\section{Conclusions and Future Scope :}

A simple microstrip patch antenna with aperture coupler technique has been succesfully designed according to design specifications, simulated and analyzed. The design of this work gives the following results; return loss of $-34.827 \mathrm{db}$ and bandwidth of $308 \mathrm{MHz}$ at the operating frequency, The VSWR obtained is 1.036 Taken as whole, the performance of the antenna meets the desired requirements in terms of return loss and VSWR at the desired operating frequency. Although, it cab be designed using IC fabrication and can be tested using Network Analyser.

Due to small and compact size of antenna operating on $5.75 \mathrm{GHz}$ to 5.85 , has many applications in WLAN. However, the proposed design has simple structure and it can be constructed with a lower cost.

\section{Refrences:}

[1] M.T.Ali, S.Muhamud@ kayat, N.R.Abd Rahman and Norsuzila Ya'cob, "A Microstrip Patch Antenna with Aperture Coupler Technique at 5.8GHz”, IEEE International Conference on system Engineering \& technology (ICSET) 2011.

[2] C.A Balanis, Antenna Theory, $3^{\text {rd }}$ edition, John Wiley \& Sons, Hoboken, NJ, 2005.

[3] Ramesh Garg, Prakash Bharti, Inder Bahl, Microstrip Antenna Design Handbook, Artech House, Boston London,2000

[4] Randy Bancroft, Microstrip Antenna, The Analysis \& Design of Microstrip Antennas and Arrays, $2{ }^{\text {nd }}$ Edition, 1995 . 